\title{
Electronic Storybooks for Young Children: Valuable Educational Tool or just Entertaining?
}

\author{
Marilena Savva \\ School of Education, Durham University (UNITED KINGDOM)
}

\begin{abstract}
There is no doubt that stories read to young children are one of the most important sources of language and literacy development. Listening to stories, children expand their story comprehension skills and acquire sophisticated language in addition to code-related skills such as phonological awareness or concepts of print. In a world in which media dominate our daily lives, young children spend a lot of time with on-screen activities (i.e., watching television, playing computer games, listening to stories) at the expense of reading print books. Most of the electronic story books (e-books) aimed at young children are equipped with interactive and multimedia features, e.g. written text, oral reading, background music and sounds, hotspots activating animations, video, on-demand word definitions, synonyms, and other functions that may support language and literacy development in unique ways. Another potential benefit of e-books is that they can be motivating, particularly for reluctant readers as well as for children with learning difficulties. However, it is unclear if the entertaining, interactive and multimedia features of e-books only foster a positive attitude toward literacy temporarily - until the novelty wears off-or if the motivational aspects of e-books can sustainably support increased engagement, and thereby literacy development. This article assesses the efficacy of e-books with a meta-analysis. The present meta-analysis proposes to compare children's language and literacy development from narrative electronic storybooks to more traditional presentation of print stories without the support of an adult.
\end{abstract}

Keywords: Electronic storybooks, e-book, digital book, multimedia book, interactive book, literacy development, young children 